\title{
REPRESENTAÇÕES SOCIAIS DE PROFESSORES RECÉM-LICENCIADOS EM LETRAS E(M) MOSTRAS DE (RE)CONSTRUÇÃO IDENTITÁRIA DOCENTE
}

\author{
Patricia Silva Santos ${ }^{*}$ \\ Fernanda de Castro Modl ${ }^{* *}$
}

RESUMO: Neste trabalho, apresentamos posições de professores de línguas recém-formados por uma mesma instituição de ensino, a Universidade Estadual do Sudoeste da Bahia, campus Vitória da Conquista. O que fazemos para refletir sobre movimentos enunciativos que informam sobre (re)construção identitária do profissional professor, bem como para delimitar representações sociais desse grupo. Para tanto, analisamos discursivamente, em posições de 3 (três) sujeitos, o que eles dizem a respeito do seu trabalho, desde o ingresso na graduação até o exercício da profissão. No trabalho com esses dizeres: i) acessamos representações sociais sobre a profissão; ii) demonstramos a validade do instrumento de pesquisa questionário discursivo para gerar e lidar com dizeres que indiciem movimentos de (re)construção identitária relativos à figura professor (Modl; Ribeiro, 2015) e iii) apostamos na importância de pesquisas que versem sobre identidades profissionais docentes em consonância com o estudo das representações sociais para as agendas de pesquisa no campo da Linguística Aplicada.

PALAVRAS-CHAVE: Identidades profissionais; Profissão professor de línguas; Representações sociais.

\footnotetext{
* Mestrando Em Letras: Cultura, Educação e Linguagens pela Universidade Estadual do Sudoeste da Bahia (Uesb).

** Professora Titular da Universidade Estadual do Sudoeste da Bahia (Uesb). Doutora em Linguística e Língua Portuguesa pela Pontifícia Universidade Católica de Minas Gerais (PUC-MG).
} 


\section{Introdução}

Em Linguística Aplicada, já encontramos um expressivo número de pesquisas que se voltam para o estudo de identidades dos atores sociais da sala de aula - professores e alunos (KLEIMAN, 1998; CELANI; MAGALHÃES, 2002; BOHN, 2004; TÁPIAS-OLIVEIRA, 2005; KLEIMAN; VIANNA; DE GRANDE, 2013; LIMA; SOUZA, 2016; AMARAL; MODL; RIBEIRO, 2015; COELHO, 2011). Nessas pesquisas, cada qual constituída por seus quadros teórico-metodológicos específicos, percebemos um interesse em comum: compreender aspectos que, num processo ininterrupto de construção, alinhavam e dão moldes às posições dos sujeitos professores e/ou alunos, protagonistas do/no processo de ensino-aprendizagem.

Alinhadas a essas pesquisas, neste trabalho, direcionamos a nossa voz para discorrer sobre o processo de construção identitária de professores de línguas. O que fazemos apostando no estudo de representações sociais, em consonância com a Teoria das Representações Sociais (TRS), como um caminho profícuo para se acessar, em dizeres de sujeitos, traços identitários.

Interessamos, especificamente, em pesquisar indícios identitários da profissão professor de línguas (entre)vistos em posicionamentos discursivos de professores formados por uma mesma instituição de ensino, a Universidade Estadual do Sudoeste da Bahia (UESB), campus Vitória da Conquista, em respostas ao instrumento de pesquisa questionário discursivo por nós elaborado ${ }^{1}$.

Dizeres de professores recém-saídos ${ }^{2}$ da graduação interessam-nos, pois guardam, se pensamos em uma memória de trabalho, lembranças mais recentes de vivências na formação inicial, o que, acreditamos, pode informar diferentemente (per)cursos formativos,

${ }^{1} \mathrm{O}$ instrumento integra a pesquisa de mestrado em andamento, já tendo sido apreciado pelo CEP (Comitê de Ética em Pesquisa) UESB e aprovado $\left(\mathrm{N}^{\circ}\right.$ do parecer 3.092.331). Aqui, deteremo-nos à análise de respostas de três sujeitos a duas perguntas do instrumento.

${ }^{2}$ Por professores recém-saídos da graduação, compreendemos o período de até três anos após a conclusão da licenciatura. 
bem como sobre feelings que o exercício do trabalho tem proporcionado ao olharem para a sua profissão.

Trata-se, então, aqui, de um olhar para a pesquisa que percebe o processo de construção identitária do professor de línguas pelo viés da importância dos espaços sociointeracionais nos quais ele transita para receber a outorga da profissão, bem como para exercê-la - os campos universitários e a escola, local de trabalho.

À vista da construção deste nosso projeto de dizer, apresentamos, nas seções que se seguem, o referencial teórico da nossa pesquisa maior em curso, no qual mobilizamos princípios teóricos advindos de diferentes áreas do saber; o percurso metodológico adotado para a construção de um corpus de pesquisa; em seguida, apresentamos a nossa análise discursiva das respostas dos três sujeitos a duas perguntas do questionário seguida pela nossa leitura dos afastamentos e aproximações de representações sociais dos sujeitos (entre)vistas a partir do cruzamento de suas respostas. O que, por sua vez, nos autoriza a tematizar sobre reconstruções identitárias. Concluímos o trabalho com a elucubração da validade de tal abordagem para o campo aplicado da linguagem.

\section{Identidades e identidades profissionais docentes: uma construção sociointeracio-} nal

Vivemos em um momento marcado essencialmente por mudanças dos mais diversos níveis - culturais, tecnológicas, políticas, sociais. Adjetivado por modernidade tardia (HALL, 2006), esse momento se plasma por uma nova ordem cultural, na qual "a linguagem, os textos, as línguas, e as pessoas movem-se cada vez mais” (MOITA LOPES, 2013, p. 18). Tal movência ocorre nos diversos espaços sociointeracionais nos quais exercemos nossos papéis sociais. Assim, nossos modos de ser e de (res)significar as coisas do/no mundo vão sendo constituídos por um caráter dinâmico, plástico, e se ajustam às mudanças sociais previsíveis à modernidade.

Hall (2006, p. 7) defende que o sujeito pós-moderno, inserido nesse espaço-tempo específico, enfrenta uma crise de identidade, tida como "parte de um processo mais amplo 
de mudança, que está deslocando as estruturas e processos centrais das sociedades modernas e abalando os quadros de referência que davam aos indivíduos uma ancoragem estável no mundo social". Desse modo, muito dificilmente, podemos falar que os sujeitos possuem uma identidade fixa, imóvel. Ao contrário disso, sempre somos convidados a repensar aquilo que somos, seja por nós mesmos ou pelas instâncias sociais que exigem de nós novos modos de ser e agir.

Inseridos em espaços sociais múltiplos, a todo o momento, vivenciamos um intercâmbio de papéis sociais: por exemplo, ora somos filhos, ora somos pais, em determinado momento, somos professores e, em outros, somos alunos. Sobre essa assunção de papéis e identidades distintas, Woodward (2000) explica que as mudanças e formação de identidade também acontecem no nível local e pessoal. A autora, ancorada em Hall (1997), diz que

Embora possamos nos ver, seguindo o senso comum, como sendo 'a mesma pessoa' em todos os nossos diferentes encontros e interações, não é difícil perceber que somos diferentemente posicionados, em diferentes momentos e em diferentes lugares, de acordo com os diferentes papéis sociais que estamos exercendo [...]. Diferentes contextos sociais fazem com que nos envolvamos em diferentes significados sociais. (WOODWARD, 2000, p. 28)

Outro ponto levantado pela autora em relação à questão da identidade diz respeito ao seu caráter relacional. As pessoas, em suas relações sociais, vão construindo meios de pertença a grupos sociais a depender dos modos como os representam simbolicamente, o que significa que elas encontram diferenças entre esses grupos, levando-as à afirmação ou à negação de pertencimento. Assim, uma identidade é sempre relacional e a diferença identitária "é marcada por representações simbólicas que atribuem significado às relações sociais, mas a exploração da diferença não nos diz por que as pessoas investem nas posições que elas investem nem por que existe esse investimento pessoal na identidade [...]" (WOODWARD, 2000, p. 54). 
O que podemos perceber, pelas nossas experiências intersubjetivas, é que “identificamos com certas ideias, com certos assuntos, com certas afirmações, porque temos a sensação de que elas ‘batem’ com algo que temos em nós”. (ORLANDI, 1998, p. 206). No percurso da vida, diferentes ideias vão 'batendo' em nós, tornando-nos numa espécie de mosaico formado por diferentes identidades que construímos ao longo do tempo. A identidade é, assim, interacional, pois se constrói no curso das interações, nos diferentes espaços sociais nos quais interagimos com os outros.

Kleiman (1998), atenta às questões de identidade, convida-nos a olhar para as relações de poder como elementos constituintes no processo de construção identitária, característicos das interações intersubjetivas. Daí a emergência do caráter movente e plástico da identidade, pois se constroem de acordo com as condições interacionais estabelecidas. Nessa direção, a identidade é tida

[...] não como uma condição permanente, mas como uma condição transitória e dinâmica moldada pelas relações de poder que, na percepção dos participantes, estão sendo configuradas na interação. Em outras palavras, consideramos que nesse contexto a manifestação simbólica da diferença, através da prática discursiva, é socialmente construída, e não necessariamente em cima de princípios racionais de cooperação e de negociação de sentidos. (KLEIMAN, 1998, p. 280)

As relações de poder emergidas no seio das instituições sociais, nesse sentido, contribuem para contornar traços às identidades dos sujeitos. As instituições, desse modo, exercem um papel privilegiado na criação de identidades, porém não exercem um papel totalizante (KLEIMAN, 1998). De certo, nossas identidades constituem-se na medida em que nos relacionamos com o outro em espaços históricos, culturais e sociais, de acordo com as condições institucionais nesses espaços estabelecidas. Contudo, o próprio caráter dinâmico das interações e das relações que delas se estabelecem oferece recursos de autonomia para os sujeitos reinventarem suas ações sociais, dando espaço para a construção de outras identidades. 
Assim, entendemos que "a construção da identidade está determinada pelas relações de poder entre os grupos sociais, mas divergimos de um conceito de identidade baseado apenas na ordem social preestabelecida, tal qual dada pelas relações de poder entre grupos sociais" (KLEIMAN, 1998, p. 281).

Sendo a realidade social construída no veio das instâncias institucionais, porém não totalmente restritas a elas, de que modo e em que medida os atributos institucionais determinam e/ou condicionam identidades?

Bohn (2004), numa pesquisa que aborda a construção social das identidades de professores de línguas, demonstra-nos que diferentes vozes são importantes para a construção da identidade do professor de línguas: a dos professores universitários, a dos autores dos textos que circulam na sala de aula, a das instituições que se manifestam nos projetos políticos pedagógicos, a voz da sociedade, a dos colegas de profissão e, não menos importante, a voz da família.

Ao focalizarmos em identidades profissionais de professores de línguas, percebemos, assim como Bohn (2004) o faz, que diversas são as vozes que contornam os traços identitários desses sujeitos, contudo, levamos em conta o campo universitário como lugar privilegiado da formação identitária docente. É lá que o sujeito adquire a certificação que o licencia para o trabalho com a docência. Não podemos esquecer também da escola, seu local de trabalho, como lugar significativo de constituição de sua identidade. É lá, no ambiente escolar, que o professor estabelece relações com seus alunos, com seus colegas de trabalho e põe em prática os conhecimentos construídos na universidade.

\section{A sala de aula universitária e o local de trabalho como balizadores para a construção identitária do professor}

$\mathrm{Na}$ cultura escolar brasileira, para tornar-se um professor, privilegiadamente, é preciso que as pessoas ingressem num curso de licenciatura. Os cursos de licenciatura são, 
assim, cursos de letramento de professores (ASSUNÇÃO, 2016), eles “oportunizam a formação para o exercício de uma profissão, a profissão de professor, por meio de formação política, técnica, filosófica e conceitual”. (BARRETO; SOUZA, 2016, p. 96)

A licenciatura em Letras é o curso que forma sujeitos para o trabalho com o ensino de língua(s). Nesse curso, “os processos de (re)configurações identitárias dos professores em formação estão marcados por ações e reações encadeadas e desencadeadas em torno da linguagem enquanto objeto de investigação, de ensino, de estudo e artefato de trabalho" (ASSUNÇÃO, 2016, p. 55).

Assim, a sala de aula universitária do curso de licenciatura em Letras é lugar genuíno de construção identitária do professor de línguas. É lá, nos campos universitários, a partir do processo de sociabilização com os professores universitários, do aprendizado e discussão de conhecimentos relativos à linguagem, à literatura e a metodologias de ensino, que o professor em formação vai aprendendo o saber-fazer docente que o ensino de línguas implica.

Assim, ao receber o certificado de conclusão do curso de licenciatura, o sujeito que cursou ao longo de quatro anos a graduação em Letras recebe o título de professor de línguas. A terminalidade do curso, então, significa a possibilidade de outorga de grau e inserção desse sujeito na profissão docente (BARRETO; SOUZA, 2016).

Em relação ao ensino oferecido nos centros acadêmicos à formação de professores, cabe ressaltarmos uma diferença terminológica que se desencadeia em uma diferença conceitual: os termos formação inicial e formação continuada. Até aqui, temos tematizado sobre a formação inicial do professor, tida como todo o tempo do curso de licenciatura que se conclui na terminalidade do curso. Nesse caminho, a formação continuada diz respeito aos cursos de pós-licenciatura. São cursos oferecidos para sujeitos que já são professores. Segundo Barreto e Souza (2016, p. 105), esse tipo de formação deve propiciar "não só novos e mais conhecimentos, mas considerar a partilha, a troca de experiências que o exercício da profissão oportuniza para a construção coletiva de conhecimento sobre a docência, a gestão da autonomia e da liberdade na escola, na sala de aula, na aula”. 
Nos dois casos, é importante também focalizar no sentido do termo 'formação', haja vista que, tanto em cursos de formação inicial como em cursos de formação continuada, a importância a ser centralizada recai nas ressonâncias provocadas nos sujeitos ao passarem por esses cursos. Dialogamos com noção de Barreto e Souza (2016), na medida em que as autoras pensam em formação não num sentido técnico, como um processo de adquirir conhecimentos acadêmicos a desposá-los na atuação do trabalho, mas num sentido reflexivo, que vê a capacitação docente, em estágio de formações inicial e continuada, como formação constituída no mundo pessoal e profissional dos sujeitos, como lugares de subjetivação. Nas palavras das autoras,

A formação apela a um enunciar de concordância ou discordância, antes situações de aprendizagem e ensino pelo próprio sujeito, de questões que se (re) apresentam como consubstanciadoras de seus desejos de aprender a estar na profissão professor. Não se restringem aos objetivos da proposta apresentada para o curso, pois não pertencem exclusivamente ao domínio dos propositores com os quais estabelece relação, mas, fundamentalmente, ao domínio da subjetividade consigo próprio e com os outros, em processos dialógicos de construção de conhecimento que cria uma ligação entre o ser e o fazer, o ser e o saber: a vivência, a prática, o conhecido e o a se conhecer/interpretar. (BARRETO; SOUZA, 2016, p. 100)

Como propusemos a mostrar no interior desta seção, vemos a sala de aula universitária, por meio da formação inicial e continuada, como espaço privilegiado para a construção e reconstrução identitária de professores. As atividades desencadeadas nesse espaço de formação propiciam aos licenciandos conhecimentos necessários para a atuação como docentes. Lá, representações cristalizadas pelo veio do senso comum vão cedendo espaço a representações acadêmicas que garantirão aos professores, senão os conhecimentos suficientes para o exercício do trabalho, pelo menos conhecimentos necessários para ressonância nos sujeitos de como podem lidar com as particularidades do ensino de línguas. Assim, ao receber a certificação da conclusão de curso de licenciatura, os sujeitos já podem ingressar na profissão docente, são professores. 
À característica móvel e plástica do processo de construção identitária docente, não podemos deixar escapar a possibilidade de espaços outros como constituintes para a construção da identidade profissional do professor. Aqui, sem dúvida alguma, estamos direcionando o olhar para a escola, local no qual a atuação profissional docente, de fato, é exercida. A sala de aula, espaço da escola em que professores e alunos exercem seus papéis sociais, o que fazem por meio de trocas didáticas (COELHO, 2011), promove a construção do conhecimento, assim como permite a delineação de contornos identitários a esses sujeitos.

O professor recém-licenciado, ao ingressar na escola, é composto por saberes acadêmicos necessários à sua profissão, compartilha representações construídas ao longo de sua vida e, principalmente, ao longo de sua formação à docência. Esses saberes acadêmicos advêm das leituras e discussões propiciadas pela licenciatura, da sociabilização com os professores universitários e com os colegas de curso e de suas experiências com as disciplinas de estágio supervisionado, nas quais ele tem a oportunidade de participar de uma unidade letiva do ano escolar em turmas da rede de ensino pública. Nesses estágios, os professores em formação observam aulas de professores regentes, participam de atividades de coparticipação, planejam aulas e lecionam. Tal processo chega a aproximar das atividades de um professor, porém não de modo genuíno, visto que, nessas situações, os graduandos assumem o papel social de estagiários.

A escola e a sala de aula tornam-se, assim, novos espaços simbólicos para esse sujeito, visto que é lá que ele exercerá, na prática cotidiana, suas tarefas profissionais docentes. Desse processo de novas experiências e de novas relações sociais, podem surgir conflitos, caso as representações que circulam no ambiente de trabalho não sejam as mesmas que o professor compartilha, se as imagens que ele concebeu sobre o ensino, a escola e/ou alunos não condizerem com a nova realidade que se instancia. Aqui, então, tematizamos sobre situações de conflito como situações em que a cooperação não sintetiza as relações sociais - o encontro do professor com uma realidade já prevista seria uma situação de cooperação. Kleiman (1998), num estudo sobre construção identitária de analfabetos, garante que o conflito é um elemento característico das interações. A autora argumenta que 
Quando consideramos a interação de grupos muito diferenciados quanto a seus valores, crenças e atitudes, em que há marcada assimetria entre os participantes em relação ao poder e às normas institucionalmente determinadas, o conflito é a norma e não a exceção. [...] Daí mantermos que o conflito é constitutivo na interação quando os participantes pertencem a grupos sociais muito diferentes. (KLEIMAN, 1998, p. 279)

O professor, ao iniciar seu trabalho na escola, adentra-se nesse espaço social, que é constitutivo pela sua própria organização, sua própria cultura: a cultura escolar. Cultura essa que já lhe foi comum em tempos anteriores, porém na condição de aluno. No exercício da profissão, estabelecem-se novos relacionamentos com esse espaço, bem como saberes profissionais vão se construindo.

Tardif e Raymond (2000) tematizam sobre os conhecimentos advindos essencialmente da prática profissional do professor na escola. Esses saberes são fruto da relação entre o profissional e o seu trabalho, nascem da prática cotidiana a fim de darem sentido às situações de trabalho. Cabe informar que os autores não excluem os saberes apreendidos durante as formações inicial e continuada, mas veem os conhecimentos próprios da vida cotidiana da escola como uma complementação da identidade profissional do professor. Assim, segundo eles,

raramente acontece que essa formação teórica não tenha de ser completada com uma formação prática, isto é, com uma experiência direta do trabalho, experiência essa de duração variável e graças à qual o trabalhador se familiariza com seu ambiente e assimila progressivamente os saberes necessários à realização de suas tarefas". (TARDIF; RAYMOND, 2000, p. 210)

Nesse viés, ao mesmo tempo em que o professor trabalha, ele (re)constrói, a partir das vivências da prática de ensino, traços para a sua identidade profissional. O trabalho, desse modo, "modifica a identidade do trabalhador, pois trabalhar não é somente fazer alguma coisa, mas fazer alguma coisa de si mesmo, consigo mesmo". (TARDIF; RAYMOND, 2000, p. 209-210). 
O tempo, nessa medida, é um elemento crucial, pois é por meio das experiências propiciadas pela atuação docente, que o professor vai construindo saberes necessários para a lida no espaço escolar, criando representações de como deve ser o seu trabalho.

\section{Traços identitários (e)m representações sociais}

A Teoria das Representações Sociais surge no escopo da Psicologia Social, a partir dos estudos do psicólogo Serge Moscovici, que tinha como propósito "compreender mais profundamente de que forma a psicanálise, ao sair dos grupos fechados e especializados, é ressignificada pelos grupos populares” (OLIVEIRA; WERBA, 1998, p. 104-105). As considerações dessa teoria, no entanto, não se restringem somente aos campos da Psicologia, longe disso, cada vez mais, têm ganhando espaço e força nas mais diversas áreas, tendo em vista que ela permite "entender e interpretar os fenômenos sociais, ajudando a compreender por que as pessoas fazem o que fazem" (OLIVEIRA; WERBA, 1998, p. 104).

Moscovici (2015) apresenta que, com o intuito de tornar familiar algo não familiar, as pessoas, em convívio com as outras, criam meios de significar, mesmo que inconscientemente, tudo aquilo que as circula, ou seja, reagem a pessoas, objetos, fenômenos ou acontecimentos, atribuindo-os características, valores, sentidos.

As representações são, assim, sistemas de significação que contribuem para o entendimento comum de determinado objeto e, além disso, contribuem para a comunicação dos sujeitos que fazem parte desse mesmo sistema de percepção. Elas são um "modo que cria tanto a realidade como o senso comum” (MOSCOVICI, 2015, p. 49). O caráter plástico dessas representações pressupõe a sua mobilidade: elas são recriadas e ressignificadas no curso das interações. A criação das representações, dessa maneira, não acontece de modo isolado, uma vez que estamos expostos e perpassados por realidades que só existem por meio de convenções (pre)estabelecidas pelas nossas culturas ou por aquelas às quais temos acesso. Isso permite-nos entender a fala de Moscovici quando diz que "enquanto essas representações, que são partilhadas por tantos, penetram e influenciam a mente de 
cada um, elas não são pensadas por eles; melhor, para sermos mais precisos, elas são repensadas, re-citadas, e re-apresentadas" (MOSCOVICI, 2015, p. 37).

As considerações de Moscovici são muito importantes para o surgimento dos estudos sobre as representações sociais, podemos dizer que o psicólogo introduz o que há de necessário para compreendermos esses fenômenos de percepção e significação. Contudo, as investidas nessa teoria não param por aí: outros pesquisadores, interessados pelas peculiaridades e relevância dessa teoria no entendimento dos fenômenos sociais, ampliam o seu quadro conceitual.

Abric (1986) é um dos pesquisadores que amplia esse quadro e apresenta a pertinência desses estudos para o entendimento de identidades, tema ao qual a nossa pesquisa se interessa. Ao fazer investigações em relação ao modo como representações sociais interferem nos comportamentos dos sujeitos, o autor as atribui quatro funções, quais sejam:

(i) função do saber - elas possibilitam aos atores sociais assimilarem conhecimentos diante do quadro de valores aos quais eles aderem; (ii) função identitária - elas conferem ao grupo social traços identitários, colocando-se como referência para as ações dos membros desse grupo; (iii) função de orientação - elas se prestam a guiar as ações e, assim, a definir finalidades e antecipar reações; (iv) função justificativa - elas permitem aos atores sociais explicarem e justificarem comportamentos, opiniões, tomadas de posicionamentos. (ABRIC, 1986, p. 15-18 apud RIBEIRO, 2008, p. 60- 61, grifos nossos)

Desse modo, o pesquisador demonstra-nos a aplicabilidade da teoria para os estudos sobre identidades, uma vez que uma das funções das representações sociais, por ele delimitadas, é justamente fornecer traços identitários aos grupos sociais. Jodelet (1993) parece concordar com tal premissa, na medida em que apresenta que

Reconhece-se, geralmente, que as representações sociais, como sistemas de interpretação, que regem nossa relação com o mundo e com os outros, orientando e organizando as condutas e as comunicações sociais. Igualmente intervêm em processos tão variados quanto a difusão e a assimilação dos conhecimentos, no desenvolvi- 
mento individual e coletivo, na definição das identidades pessoais e sociais, na expressão dos grupos e nas transformações sociais. (JODELET,1993, p. 5, grifos nossos)

A partir das considerações de Jodelet (1993) e Abric (1986), descritas acima, podemos considerar que o estudo sobre representações sociais de um determinado grupo é crucial para o entendimento de suas identidades. Atentas a isso, ao propormos uma pesquisa que aborde traços identitários de sujeitos que fazem parte do sistema educacional de ensino de línguas (Português/Inglês) de uma cultura local, sejam como profissionais já ativos no ofício de ensino, sejam como profissionais que estão à espera de oportunidades para adentrarem a sala de aula, pensamos, desde o início, na TRS como um dos aportes teóricometodológicos para o delineamento do trabalho.

Em nossa pesquisa, que consiste em mapear e analisar traços identitários de professores de línguas, essa teoria contém um papel significativo, na medida em que pode permitir-nos compreender o modo como esses sujeitos percebem o seu trabalho, o objeto de ensino com o qual trabalham e como reagem às demandas que os foram apresentadas desde a graduação até o seu (re)agir em sala de aula.

Se a identidade do sujeito professor não é una, ao contrário disso, é institucionalmente construída e se constitui na multiplicidade de diferentes vozes, a partir de diferentes espaços sociais (HALL, 2006; KLEIMAN, 1998; BOHN, 2004), vemos as representações sociais como o caminho e a chegada para acessar traços identitários profissionais desses sujeitos. Percebemos, assim, que "é por meio dos significados produzidos pelas representações que damos sentido a nossa experiência e àquilo que somos" e que "esses sistemas simbólicos tornam possível aquilo que somos e aquilo no qual podemos nos tornar" (WOODWARD, 2000, p. 17).

Além disso, percebemos, assim como faz Crusoé (2004), que os sujeitos da prática pedagógica são sujeitos sociais, cognitivos, afetivos. E, por isso mesmo, são sujeitos que possuem identidades (re)construídas no curso das interações sociais. Assim, podemos dizer que identidades acompanham o fluxo móvel das representações sociais: as pessoas, ao (re)criarem representações, (res)significam seus modos de ser, ou seja, suas identidades. 
Ademais, compartilhamos das ideias de que essas representações "são tudo o que nós temos, aquilo a que nossos sistemas perceptivos como cognitivos, estão ajustados [...]" (MOSCOVICI, 2015, p. 32) e, além disso, constituem-se "como um objeto de estudo tão legítimo [...] por sua importância na vida social, pelos esclarecimentos que traz acerca dos processos cognitivos e as interações sociais" (JODELET, 1993, p. 5).

\section{Percurso metodológico}

$\mathrm{Na}$ pesquisa maior, interessamo-nos por traços identitários da profissão professor de línguas (entre)vistos nos posicionamentos discursivos de professores formados pela UESB, campus Vitória da Conquista. Esses posicionamentos, por sua vez, estão ancorados em representações sociais diversas relacionadas a um espectro maior de trabalho do professor de língua(s).

À vista de lidarmos com esse objetivo, apostamos no questionário discursivo como um dos instrumentos de pesquisa, uma vez que ele possibilita que os sujeitos discursivizem a respeito do seu trabalho, a partir de perguntas abertas que não delimitam os seus dizeres, no máximo, os focalizam na direção daquilo que foi perguntado. Ademais, percebemos, assim como Coelho (2011), o diferencial desse instrumento de pesquisa de acessar posições de diferentes sujeitos em um mesmo espaço de tempo.

O questionário respondido pelos professores é composto por sete perguntas discursivas. No entanto, neste trabalho, iremos apresentar a análise discursiva de duas dessas perguntas, quais sejam: i) Você consegue se lembrar de como você via a profissão do professor de línguas antes do ingresso no curso de Letras e durante o curso de Letras? O que você diria sobre o modo como você percebe a nossa profissão hoje? e ii) Para você, como deve ser o ensino de línguas?.

Para a leitura dos dizeres dos sujeitos suscitados pelas perguntas apresentadas acima, mobilizamos categorias de análise que, assim como o nosso projeto de dizer supõe, suscitem uma interpretação discursiva, a qual ainda considere que, nas interações com o outro, 
dizemos o mundo, e o ato de dizer não é somente uma atividade cognitiva, mas incide, também, em atividades sociais, históricas e culturais (MARCUSCHI, 2004).

Nessa direção, elegemos i) o léxico; ii) a referência pessoal e iii) a pressuposição como categorias norteadoras para a análise discursiva dos dados.

Isso porque as escolhas lexicais que fazemos diariamente são histórica e culturalmente situadas e, por isso mesmo, (re)velam marcas de nossas relações intersubjetivas (MARCUSCHI, 2004). A análise do mecanismo de referência de pessoa permite-nos observar o "eu em relação ao aqui e o agora", ou seja, posicionamentos identitários dos sujeitos sendo construídos situadamente face aos efeitos que incidem em suas representações sobre si e sobre o outro (SILVA; MATENCIO, 2005). E, por fim, a pressuposição, vista aqui como o que se pode indiciar em um enunciado, permite que consideremos os implícitos de um dizer, indo além do que nele é afirmado (DUCROT, 1984).

Compreendemos, então, que os sujeitos, ao referirem sobre o seu trabalho, deixam marcas no discurso que revelam suas posições identitárias, assim como traços da cultura pela qual falam. O ato dizer, para nós, então, é revelador de subjetividades e identidades, que são sempre construídas em contato com o outro, em momentos contextualmente situados. Nesse caminho, assumimos que aquele que diz sempre o faz para alguém e, nesse processo de (inter)relação discursiva, os interlocutores constroem e reconstroem suas identidades, a partir de distanciações e similaridades com o dizer do outro.

\section{Análise dos dados}

Dando início à nossa análise discursiva dos dados, visualizemos as respostas à primeira pergunta, que, aqui, publicizamos. 
Quadro 1 - Respostas dos sujeitos à primeira pergunta

\begin{tabular}{|c|c|}
\hline Sujeito & $\begin{array}{l}\text { Resposta à pergunta: Você consegue se lembrar de como você via a profissão } \\
\text { do professor de línguas antes do ingresso no curso de Letras e durante o curso } \\
\text { de Letras? O que você diria sobre o modo como você percebe a nossa profissão } \\
\text { hoje? }\end{array}$ \\
\hline Pedro & $\begin{array}{l}\text { Eu considerava o trabalho do professor de Línguas robótico. Havia uma fór- } \\
\text { mula. Na graduação, descobri que “o buraco é mais embaixo" e que o profes- } \\
\text { sor precisa assumir diferentes faces e posturas a depender do contexto e das } \\
\text { especificidades de cada aulinha da semana. É um trabalho árduo, porém, praze- } \\
\text { roso. }\end{array}$ \\
\hline Aurora & $\begin{array}{l}\text { Não me lembro exatamente de como via a profissão, mas me lembro de querer } \\
\text { aprender línguas e esbarrar nas dificuldades da escola pública. Durante o } \\
\text { curso, meu olhar era de admiração. Tive ótimos professores de línguas, princi- } \\
\text { palmente de inglês, queria ser como eles. Atualmente, continuo tendo admira- } \\
\text { ção por nossa profissão. Vejo como uma missão importantíssima, dado que, } \\
\text { no mundo em que vivemos, é preciso preparar nossos estudantes suficiente- } \\
\text { mente, torná-los letrados, preparados para agir e interagir socialmente, principal- } \\
\text { mente por meio dessa língua franca, o inglês. }\end{array}$ \\
\hline Dilma & $\begin{array}{l}\text { Não consigo me lembrar porque a visão que temos da escola muitas vezes é } \\
\text { frustrante ou romantizada. Atualmente percebo a profissão do professor de } \\
\text { língua inglesa como uma oportunidade de abrir uma janela para o mundo, ins- } \\
\text { pirando gerações que se preocupem com o bem estar social, que possam se } \\
\text { comunicar e sociabilizar em outra língua e que na maioria das vezes é traduzido } \\
\text { na língua alvo, ou língua mundial - o Inglês. }\end{array}$ \\
\hline
\end{tabular}

Fonte: Dados da pesquisa

Percebemos, no dizer de Pedro, uma ressignificação de representações sociais propiciada pelo acesso ao ensino superior. O sujeito lança mão das escolhas lexicais 'robótico' e 'fórmula' para se referir à sua percepção da profissão professor de línguas nos anos anteriores à graduação em Letras. Esses índices lexicais permitem-nos pressupor que o sujeito percebia o trabalho docente como uma tarefa mecanizada, constituída por padrões que garantem uma estabilidade ao saber-fazer docente. O dito ‘o buraco é mais embaixo’ figura, na fala do sujeito, como uma reconfiguração do seu olhar para a profissão decorrente da sua experiência na sala de aula universitária. Desse espaço interacional genuíno de formação 
do professor, o sujeito dá contornos novos à prática docente, percebendo que ela deve ser reflexiva, orientada pelas reais necessidades que se deixam perceber na sala de aula.

Aurora, para rememorar a sua representação de professor de línguas antes de ingressar-se no curso de Letras, recorre ao seu papel social de aluna do ensino básico, focalizando seu dizer em relatos de suas experiências com a aprendizagem de língua inglesa. As escolhas lexicais 'esbarrar' e 'dificuldades' demonstram a representação de ensino de línguas na rede pública de ensino da professora construída por meio de suas vivências como aluna: a representação de que não se aprende inglês na escola. Mais a frente, ao discorrer sobre sua visão sobre o professor de línguas na graduação, Aurora projeta a imagem de seus professores universitários, referindo-os como ótimos professores e demonstrando que eles são sua referência. Por fim, ao discorrer sobre a profissão sob o olhar de professora, o sujeito atualiza conhecimentos acadêmicos no seu dizer, apontando para a importância da profissão do professor de língua inglesa uma vez que essa língua, atualmente, assume o status de língua franca. O que o faz demonstrando-nos contornos acadêmicos em sua identidade profissional.

Para referir-se ao modo como via a profissão, a professora Dilma demonstra que algumas percepções sobre a profissão de línguas que circulam no senso comum não condizem com a realidade, o que podemos pressupor por meio das escolhas lexicais 'frustrante' e 'romantizada'. E o sujeito o faz por meio da remissão à primeira pessoa do plural (nós), projetando, em sua resposta, a imagem do grupo social alunos da graduação, do qual não se exclui, reportando assim ao seu papel social de graduanda. Em seguida, a professora verte para seu papel social de professora de línguas, o que se evidencia pelo o que é posto no seu dizer através dos índices lexicais 'atualmente' e 'janela para o mundo'. Assim, o uso do advérbio temporal demonstra que houve uma ressignificação das suas percepções ao longo do tempo até o presente momento em que ela é professora. Através do uso metafórico - janela para o mundo -, fica insinuado que o sujeito percebe que um dos deveres da sua profissão é preocupar-se com um ensino que ultrapasse as paredes da escola, que faça eco nas ações cotidianas dos alunos a fim da construção de uma sociedade melhor. Dito 
que a professora constrói atualizando conhecimentos acadêmicos, explicitando a necessidade da língua inglesa por ser uma língua mundial.

Tendo apresentado a nossa análise das respostas à primeira questão, passemos agora à nossa leitura analítica das respostas à segunda pergunta:

Quadro 2 - Respostas dos sujeitos à segunda pergunta

\begin{tabular}{|l|l|}
\hline Sujeito & \multicolumn{1}{|c|}{ Resposta à pergunta: Para você, como deve ser o ensino de línguas? } \\
\hline Pedro & $\begin{array}{l}\text { O ensino de línguas deve preocupar-se, majoritariamente, na minha opinião, com } \\
\text { o contexto político-social dos alunos (e também dos professores). É preciso } \\
\text { duvidar das fórmulas, afinal, não se trata de uma receita de bolo. É preciso } \\
\text { discursivizar as aulas, isto é, fazer com que os alunos sintam, empiricamente, o } \\
\text { poder da(s) língua(s). }\end{array}$ \\
\hline Aurora & $\begin{array}{l}\text { No caso do ensino de Língua Inglesa, disciplina que leciono, deveria, antes de } \\
\text { qualquer coisa, ser levado a sério. Percebo que, tanto em escolas privadas quanto } \\
\text { em escolas públicas, a língua estrangeira é vista como uma disciplina à parte, } \\
\text { sem muita importância, que "não reprova." Acredito que, desde o início, os } \\
\text { estudantes precisam conhecer os motivos e a importância de se aprender inglês, } \\
\text { e, com motivos e objetivos definidos, a língua deva ser trabalhada de forma con- } \\
\text { textualizada, com referências em situações reais de interação. Acredito, ainda, } \\
\text { que todas as habilidades (escrita, leitura, oralidade e compreensão auditiva) de- } \\
\text { vam ser contempladas. }\end{array}$ \\
\hline O ensino de língua inglesa deveria atender a critérios mínimos de estrutura \\
para a sua devida realização. Turmas de 15 alunos, recursos audiovisuais e \\
trabalho continuo. No entanto na escola publica vivenciamos uma realidade \\
bem adversa desse perfil.
\end{tabular}

Fonte: Dados da pesquisa

Para a construção do seu dizer, Pedro recorre não somente à ilustração de como deve ser o ensino de línguas, mas, também, focaliza no que ele não deve ser pautado. Do uso metafórico - receita de bolo - que o sujeito recorre, pressupomos que o professor se investe da percepção de que o ensino não deve ser guiado por prescrições - tal qual como numa receita -, sem que haja a reflexão das experiências da sala de aula. O que fica insinuado também pela remissão às escolhas lexicais 'contexto político social' e 'discursivizar', referindo-se às aulas de línguas. Assim, pelo que é posto e pelo que podemos pressupor no 
dizer de Pedro, percebemos que o professor contorna sua identidade profissional por um viés crítico-reflexivo, atento à realidade social dos sujeitos da sala de aula.

Aurora constrói o seu dizer apresentando uma representação da disciplina língua inglesa: irrelevante nas etapas de escolarização do ensino básico. É importante frisar que, ao fazer a remissão à impessoalidade no discurso, por meio da terceira pessoa do plural (eles/elas - escolas públicas e privadas), o sujeito não se inclui nessa representação, demonstrando ser uma representação do senso comum. Ao verter para a primeira pessoa eu - por meio do índice verbal 'acredito', a professora expõe sua posição: a de que o ensino de línguas deve focalizar em situações reais de uso, abordando todas as habilidades comunicativas. Por a professora trabalhar atualmente na rede privada de ensino, percebemos que, ao trazer para o seu discurso, ao mesmo tempo, o que é institucionalizado pela escola e a sua percepção sob essa temática no papel de professora em exercício, o sujeito alinha a sua identidade docente, numa espécie de negociação entre o que é comum no espaço escolar e o seu ponto de vista.

A professora Dilma, por sua vez, verte sua resposta para um desenho ideal do que seja uma organização escolar para o ensino de línguas: turmas com 15 alunos, recursos audiovisuais e trabalho contínuo. Fica insinuado, então, no que é posto em seu dizer, que a escola não oferece tais recursos, o que dificulta o ensino de língua inglesa. É interessante notar que a professora, tendo experiência em escolas das redes pública e privada, atrela essa realidade para a escola pública. Desse modo, o sujeito recorre à sua experiência nos ambientes de trabalho para delinear um traço da sua identidade profissional: a insatisfação com a estrutura dos espaços escolares da rede pública de ensino.

\section{Aproximações e distanciamentos identitários (entre)vistos nos dizeres dos profes-} sores

Do gesto de análise das respostas dos três sujeitos, ainda consideramos importante trazer alguns pontos em relação aos seus dizeres que ora distanciam-se e ora aproximamse. Na fala de Pedro, ao referir-se ao modo como vê a profissão professor de línguas, o 
sujeito recorre à impessoalidade no discurso (o professor/ele) fazendo o uso de locuções verbais com valor deôntico (precisa assumir/é preciso duvidar/é preciso discursivizar), demonstrando qual é a atribuição de um professor. Percebemos que as escolhas linguísticas de Pedro, nesse caso, atrelam-se especificamente ao seu perfil docente construído por vivências, na maior parte do tempo, na sala de aula universitária. O sujeito, ao terminar a graduação, teve o seu ingresso num curso de pós-graduação, a nível de especialização, com poucas experiências em sala de aula. Em seu dizer, assim, predomina marcas de um fazerdocente constituído principalmente pelas vozes dos professores universitários assim como as dos autores que leu durante a graduação. Sua identidade profissional docente é construída, então, majoritariamente pelos espaços universitários.

Já Aurora e Dilma referem-se à profissão recorrendo à primeira pessoa do discurso, o que fica notado a partir do uso de verbos conjugados em primeira pessoa (vejo/percebo/acredito/vivenciamos), o que o fazem assumindo seus papéis de professoras que estão em exercício. As duas professoras também atualizam conceitos que são tematizados na universidade (língua inglesa como língua franca/mundial) atrelados à importância da disciplina que lecionam. Aurora, atualmente trabalha na rede privada de ensino em turmas de ensino fundamental; quando concluiu o curso de Letras, logo ingressou num programa de Mestrado, o qual já foi concluído. Dilma, concluiu o curso de Letras neste ano, ainda não ingressou em nenhum curso de pós-graduação e trabalha na rede pública de ensino, em turmas de Ensino Médio. Ao analisarmos as respostas das duas professoras, percebemos, então, que suas identidades profissionais apresentam traços construídos nos espaços acadêmicos, porém, (res)significados no chão da escola do ensino básico, local de trabalho.

O nosso gesto de análise, empreendido pelo cruzamento das respostas dos sujeitos, demonstra que os professores formados pela mesma instituição de ensino apresentam afastamentos e aproximações identitárias, que são visualizadas por meio das representações que compartilham sobre a sua profissão. Tal ocorrência ratifica que identidades são construídas e reconstruídas contextualmente na interação, fazendo eco a diferentes vozes e em 
diferentes espaços sociais, institucionais, culturais e históricos (KLEIMAN, 1998; BOHN, 2004; HALL, 2006).

\section{Considerações finais}

Nesse gesto de análise das respostas dos sujeitos a duas questões do questionário discursivo, podemos identificar diferentes representações sociais que tematizam sobre o trabalho do professor de línguas, quais sejam: i) o profissional de línguas deve ser críticoreflexivo, preocupado com as necessidades político-sociais dos sujeitos, a fim de construir uma sociedade melhor; ii) a escola não reconhece a importância do ensino de língua inglesa e iii) a escola pública não oferece recursos suficientes e exequíveis para o ensino de língua inglesa. Cabe reforçar que a noção do ensino de línguas alinhada à perspectiva crítico-reflexiva figura como o que há de recorrente nas respostas dos sujeitos, pois tal representação foi entrevista nos dizeres de dois professores em respostas a questões diferentes. Além disso, a recorrência da tematização da realidade escolar surge nas respostas de professoras que estão em exercício atualmente.

Percebemos que o trabalho com o instrumento questionário discursivo, cujos dados parciais aqui publicizamos, se apresenta como um instrumento caro para se acessar posições identitárias dos sujeitos. O que se evidencia pela recorrência, nas respostas dos sujeitos, a um transitar pelos papéis sociais que assumiram/assumem desde antes do ingresso na graduação até suas experiências no exercício da docência - o papel de aluno(a) do ensino básico, o papel de graduando em Letras, o papel de professor de línguas.

Concluímos este projeto de dizer com a noção de que a aposta no trabalho que verse sobre representações sociais de professores de línguas recém-licenciados em consonância com os estudos sobre identidade contribui para a agenda de pesquisa em Linguística Aplicada, na medida em que flagra a movência dos posicionamentos desses sujeitos em relação à profissão. Ressignificações que vão sendo feitas pelo professor ao longo de sua formação, quer seja na sala de aula universitária, por meio da formação inicial e/ou da 
formação continuada, quer seja na escola do ensino básico, local onde exerce o seu trabalho.

\title{
SOCIAL REPRESENTATIONS OF TEACHERS RECENTLY GRADUATED IN LETTERS IN/AND TRACES OF TEACHING IDENTITY (RE)CONSTRUCTION
}

\begin{abstract}
In this paper, we present some views of language teachers recently graduated from the same higher education institution, the Universidade Estadual do Sudoeste da Bahia, campus Vitória da Conquista. What we do in order to ponder over enunciative movements that enlighten the teachers' professional identity (re)construction, as well to delimit social representations of this group. In order to do so, we discursively analyze, in views of three subjects, what they say about their work, since their admission in the graduation program until the exercise of their profession. Working with these teachers' sayings, i) we access social representations about their profession; ii) we demonstrate the validity of the research instrument discursive questionnaire to generate and deal with sayings that indicate movements of teachers' professional identity (re)construction (Modl; Ribeiro, 2015) and iii) we bet on the importance of researches which discuss professional identities in line with the social representations study for the research agenda in the field of Applied Linguistics.
\end{abstract}

KEYWORDS: Professional identities; Language teacher profession; Social representations.

\section{REFERÊNCIAS}

AMARAL, M. S.; MODL, F. C. Questões relacionadas à identidade de gênero na pauta da formação inicial do professor: lacunas e presenças. In: LIMA, A. M. O.; SOUZA, E. M. F. (Orgs.). Letramentos e discursos em (dis) (com) posições identitárias. Coleção ECAL: Estudos Críticos e Avançados da Linguagem - Volume 7. Campinas, SP: Pontes Editores, 2016, p. 99-119.

ASSUNÇÃO, E. T. C. Os letramentos acadêmico e do professor e $(m)$ gestos formativos: a disciplina Seminário Interdisciplinar de Pesquisa (SIP) como locus de investigação /.260f. Dissertação (mestrado) - UESB, Vitória da Conquista, 2016.

BARRETO, D. A. B.; SOUZA, E. M. F. Em torno da noção de formação continuada de docentes: a terminalidade de curso e o exercício da profissão como balizadores. In: LIMA, A. et al. Educação e formação docente: reflexões filosóficas, estéticas, políticas e étnicoraciais. Editora CRV: Curitiba. PR. 2016.

BOHN, H. I. A formação do professor de línguas - a constituição de uma identidade profissional. Investigações - Linguística e Teoria Literária, v. 17, n. 2, p. 97-114, 2004. 
CELANI, M. A. A.; MAGALHÃES, M. C. C. Representações de professores de inglês como língua estrangeira sobre suas identidades profissionais: uma proposta de reconstrução. In: MOITA LOPES, L. P. da.; BASTOS, L. C. (Orgs.). Identidades: recortes multi e interdisciplinares. Campinas, SP: Mercado de Letras, 2002, p. 319-338.

COELHO, F. C. B. Construção identitária e $(m)$ comportamentos na sala de aula: o agenciamento da palavra em dois grupos (um alemão e um brasileiro). Tese (Doutorado). Pontifícia Universidade Católica de Minas Gerais, Belo Horizonte: 2011.

DUCROT, O. Pressuposição e alusão. ENCICLOPÉDLA Einaudi: Linguagem e Enunciação. Lisboa: Imprensa Nacional - Casa da Moeda, 1984, v.2, p. 394-417.

HALL, S. A CENTRALIDADE DA CULTURA: notas sobre as revoluções culturais do nosso tempo. Educação e Realidade. Porto Alegre, v. 22, n. 2, p. 15-46, 1997.

HALL, S. A identidade cultural na pós-modernidade. Tradução de Tomaz Tadeu da Silva, Guaracira Lopes Louro. $11^{\mathrm{a}}$ ed. Rio de Janeiro: DP\&A, 2006.

JODELET, D.: Représentations sociales: un domaine en expansion. In: D. Jodelet (Ed.) Les représentations so-ciales. Paris: PUF, 1989, pp. 31-61. Tradução: Tarso Bonilha Mazzotti. Revisão Técnica: Alda Judith Alves-Mazzotti. UFRJ- Faculdade de Educação, dez. 1993.

KLEIMAN, A. B. A construção de identidade na sala de aula: um enfoque interacional. In: SIGNORINI, I. (Org.). Lingua(gem) e identidade: elementos para uma discussão no campo aplicado. Campinas, SP: Mercado de Letras; São Paulo: Fapesp, 1998, p. 267-302.

KLEIMAN, A.; VIANNA, C.; DE GRANDE, P. "Sem querer ir contra pessoas tão ilustres...”: construção e negociação identitárias do professor entre discursos de (des)legitimação. SCRIPTA, Belo Horizonte, v. 17, n. 32, p. 173-194, $1^{\circ}$ sem. 2013.

LIMA, A. M. O.; SOUZA, E. M. F. As identidades em sala de aula: construções discursivas, apagamentos e resistência. In: LIMA, A. M. O.; SOUZA, E. M. F. (Orgs.). Letramentos e discursos em (dis) (com) posições identitárias. Coleção ECAL: Estudos Críticos e Avançados da Linguagem - Volume 7. Campinas, SP: Pontes Editores, 2016, p. 17-33.

MARCUSCHI, L. A. O léxico: lista, rede ou cognição? In: NEGRI, L.; FOLTRAN, M. J.; OLIVEIRA, R. P. de (Orgs.). Sentido e significação: em torno da obra de Rodolfo Ilari. São

Paulo: Contexto, 2004, p. 222-290.

MODL, F. C.; RIBEIRO, P. B. (Re)Construção identitária em movimentos de referenciação: representações sociais sobre o professor na formação inicial. Nonada, Porto Alegre, n. $24,1^{\circ}$ semestre, 2015 , p. 61-82.

MOITA LOPES, L. P. da. Fotografias da Linguística Aplicada brasileira na modernidade recente: contextos escolares. In: MOITA LOPES, L. P. da. (Org.). Linguística aplicada na modernidade recente: festschrift para Antonieta Alba Celani. $1^{\mathrm{a}}$ ed. - São Paulo: Parábola Editorial, 2013. p. 15-37. 
MOSCOVICI, Serge. Representações sociais: investigações em psicologia social. 11. Ed. Petrópolis, RJ: Vozes, 2015.

OLIVEIRA, Fátima O. de; WERBA, Graziela C. Representações sociais. In: STREY, M. (Orgs.). N. Psicologia social contemporânea. 4 ed. Petrópolis: Vozes, 1998, p. 104-117.

ORLANDI, E. Identidade linguística escolar. In: SIGNORINI, I. (Org). Lingua(gem) e identidade: elementos para uma discussão no campo aplicado. Campinas: Mercado de Letras, 1998, p. 203-2012.

SILVA, J. Q. G.; MATENCIO, M. L. M. Referência pessoal e jogo interlocutivo: efeitos identitários. In: KLEIMAN, A. B.; MATENCIO, M. L. M. (Orgs.) Letramento e formação do professor: práticas discursivas, representações e construção do saber. Campinas, SP: Mercado de Letras, 2005, p. 245-266.

TÁPIAS-OLIVEIRA, E. M. A construção da identidade profissional do professor e sua produção diarista. In: KLEIMAN, A. B.; MATENCIO, M. L. M. (Orgs.) Letramento e formação do professor: práticas discursivas, representações e construção do saber. Campinas, SP: Mercado de Letras, 2005, p. 165-179.

TARDIF, M.; RAYMOND, D. Saberes, tempo e aprendizagem do trabalho do magistério. Revista Educação e Sociedade, no 73, p. 209-244, 2000.

WOODWARD, K. Identidade e diferença: uma introdução teórica e conceitual. In: SILVA. T. T. da. (Org.). Identidade e diferença: a perspectiva dos estudos culturais. Petrópolis, RJ: Vozes, 2000, p. 7-72.

Recebido em: 24/08/2018.

Aprovado em: 02/02/2019. 